\title{
A mobilidade dos trabalhadores dos municípios do Extremo Oeste Metropolitano, interações metropolitanas e as redefinições regionais
}

Mobility of workers in Metropolitan Extreme West Municipalities, metropolitan interactions and regional redefinitions

La movilidad de los trabajadores en los municipios del Extremo Oeste

Metropolitano, interacciones metropolitanas y las redefiniciones regionales

La mobilité des travailleurs dans les municipalités du Extrême Ouest

Métropolitain, des interactions métropolitaines et les redéfinitions régionales

\section{André Santos da Rocha e Lirian Melchior}

\section{(2) OpenEdition}

\section{Journals}

\section{Edição electrónica}

URL: http://journals.openedition.org/espacoeconomia/16253

DOI: 10.4000/espacoeconomia. 16253

ISSN: 2317-7837

\section{Editora}

Núcleo de Pesquisa Espaço \& Economia

Refêrencia eletrónica

André Santos da Rocha e Lirian Melchior, « A mobilidade dos trabalhadores dos municípios do Extremo Oeste Metropolitano, interações metropolitanas e as redefinições regionais ", Espaço e Economia [Online], 19 | 2020, posto online no dia 01 setembro 2020, consultado o 09 setembro 2020. URL : http://journals.openedition.org/espacoeconomia/16253 ; DOI : https://doi.org/10.4000/ espacoeconomia.16253

Este documento foi criado de forma automática no dia 9 setembro 2020.

(c) NUPEE 


\section{A mobilidade dos trabalhadores dos municípios do Extremo Oeste Metropolitano, interações metropolitanas e as redefinições regionais}

Mobility of workers in Metropolitan Extreme West Municipalities, metropolitan interactions and regional redefinitions

La movilidad de los trabajadores en los municipios del Extremo Oeste

Metropolitano, interacciones metropolitanas y las redefiniciones regionales

La mobilité des travailleurs dans les municipalités du Extrême Ouest

Métropolitain, des interactions métropolitaines et les redéfinitions régionales

André Santos da Rocha e Lirian Melchior

\section{Introdução}

Desde a virada dos anos 2000, a Região Metropolitana do Rio de Janeiro experimentou profundas modificações em sua estrutura econômico-territorial desencadeadas pela confluência de uma série de investimentos públicos e privados que apostavam, em grande parte, na dinamização do potencial logístico - advindo das expectativas da finalização das obras do Arco Metropolitano do Rio de Janeiro (RJ-109/BR-493) e das obras de expansão do porto de Itaguaí; e também da atratividade de novas fábricas e negócios imobiliários, marcadamente da consolidação do COMPERJ, que dinamizaria todo um circuito logístico produtivo do petróleo na metrópole e da atratividade imobiliária dos condomínios logísticos que se implantariam em diversos territórios atravessados por importantes estradas. Todo esse cenário ganhava bastante força até 
2015, quando se sobrepõe uma estagnação econômica no estado, muito influenciada pela atmosfera econômica e política de âmbito nacional.

2 A despeito da diminuição do ritmo das transformações em curso, esse período acabou por desenhar dinâmicas internas da Região Metropolitana, cujas interações corroboraram por consolidar sub-regiões que, longe de adquirirem uma autonomia de organização interna, estão intimamente articuladas com processos metropolitanos. Muitas dessas sub-regiões já fazem parte da agenda de pesquisa de inúmeros pesquisadores no estado do Rio de Janeiro. A definição de sua composição territorial, das dinâmicas internas e da identificação de processos singulares é algo que se torna urgente para os estudos das interseções micro e macro escalares. Por isso, a compreensão da metrópole passa, necessariamente, pela análise dos elementos constituintes de suas subdivisões (a saber: a Capital, a Baixada Fluminense, Oeste Metropolitano, e o Leste Metropolitano) ${ }^{1}$.

3 Assim, os estudos regionais entrelaçados às análises em espaço e economia se tornam fundamentais porque o exercício de regionalização, como ato de constituir regiões, se revela como uma estratégia de compreensão didática da realidade espacial (HAESBAERT, 2005). No contexto contemporâneo, a necessidade de interpretar as regiões não pode ser simplificada à mera observação das regiões naturais, uma vez que diante da intensidade das relações sociais e econômicas de produção, a região, não se limita a pensar sua contiguidade espacial, mas também, nas particularidades de suas conexões e interações (THRIFT, 1996). Neste sentido, compreendemos que, a partir das particularidades que formam as "regiões" (CORRÊA, 1993), os fluxos populacionais e a dinâmica dos movimentos pendulares servem como pistas para compreender as interações que nela se realizam.

4 Segundo Corrêa, "as interações constituem como amplo conjunto complexo de deslocamentos de pessoas, mercadorias, capital e informação sobre o espaço geográfico" (CORRÊA, 2005, p. 279). Elas não podem ser vistas apenas como simples deslocamentos, pois são intrínsecos à (re)produção e transformação social e ganham alto grau de sofisticação no interior da forma de produção capitalista, pois altera significativamente a dinâmica entre fixos e fluxos (SANTOS, 2002). A maneira como as interações ocorrem materializam assimetrias que são historicamente construídas e cooperam para consolidar ou construir novas sinergias a partir das mudanças ou permanências de seus fluxos. Elas produzem "diferenciações" no espaço, desenhando as transformações e denunciando espacialidades de centralidade e integração, fornecendo assim subsídios para análises regionais.

5 A diferenciação dos processos que criam subdivisões no interior das regiões metropolitanas pode se manifestar de modos distintos. As interações espaciais, consolidadas nas dinâmicas do capitalismo contemporâneo, podem servir de guias teórico-metodológicos para pensarmos as direções, centralidades e dinâmicas de coesão e a estrutura de formação e organização territorial no interior da Região Metropolitana.

Por isso, na tentativa de compreender melhor processos e interações que constituem o contexto maior da região metropolitana do Rio de Janeiro, este trabalho tem como objetivo estabelecer uma análise sobre os fluxos da mobilidade do trabalhador dos municípios localizados no Extremo Oeste Metropolitano. Nosso objetivo é debater essas subdivisões e identificar particularidades de processos de transformação na estrutura interna na região metropolitana. Assim, a mesoescala ganhará destaque, sobretudo 
para entendermos a possibilidade de refletir sobre as interações que moldam essa subregião que se consolidou nos estudos fluminenses ao longo da última década.

7 Para isso, o presente trabalho se dividirá em três partes. A primeira é voltada para caracterização ou entendimento do que se constitui a noção de Extremo Oeste Metropolitano, fazendo uso da bibliografia produzida sobre este recorte territorial, seja no que tange à estrutura metropolitana, seja incorporando aspectos recentes sobre a mesma, em que buscamos a validade de pensar a mesoescala para analisar a estrutura metropolitana. Na segunda, traremos algumas considerações sobre mobilidade pendular e sua importância para entender as interações que se estabelecem na área estudada, sendo estas partes das interações econômico-produtivas no interior da região metropolitana, que salientam dinâmicas de integração e centralidade que revelam aspectos dessa estrutura urbana. Na terceira parte, apresentaremos os dados relativos à migração dos trabalhadores oriundos dos municípios do Extremo Oeste Metropolitano, fazendo uso dos dados disponibilizados no Censo IBGE de 2010, devidamente cartografados, com o que concluímos que esta área se manifesta com uma região estilhaçada, apresentando pequeno grau de interação interna, fortemente integrada às centralidades de outras áreas da metrópole.

\section{O Extremo Oeste Metropolitano como mesoescala para pensar a estrutura da região Metropolitana}

80 termo Extremo Oeste Metropolitano é empregado para designar os municípios da Região Metropolitana localizados na "borda" metropolitana do Estado do Rio de Janeiro, a saber: Queimados, Japeri, Seropédica, Paracambi e Itaguaí. Oliveira (2015) identificou que esses municípios passaram, ao longo da década dos anos de 2000 e parte de 2010, por transformações econômicas e territoriais que se enquadram num processo de "Reestruturação Territorial Produtiva".

O processo que permitiu desenhar essa sub-regionalização está relacionado a mudanças relativas: [a] a ampliação do potencial logístico devido a confluência de três vias de circulação - Rodovia Presidente Dutra - BR-116; Antiga Rodovia Rio São Paulo - BR465; e o Arco Metropolitano do Rio de Janeiro - RJ-109, como continuidade da BR-493 somadas às ações de ampliação e revitalização do Porto de Itaguaí; [b] à forte dinâmica de especulação fundiária pela valorização de terrenos localizados ao longo destas rodovias, que estão sendo destinados às novas atividades industriais, hoteleiras e imobiliárias em geral; [c] a atratividade de novos empreendimentos fabris e reanimação de áreas já consolidadas, tais como o Parque Industrial de Queimados e o Parque Industrial de Santa Cruz, localizado no Município do Rio de Janeiro. (Figura 1). 
Figura 1 -Extremo Oeste Metropolitano. Localização e vias de circulação - 2020

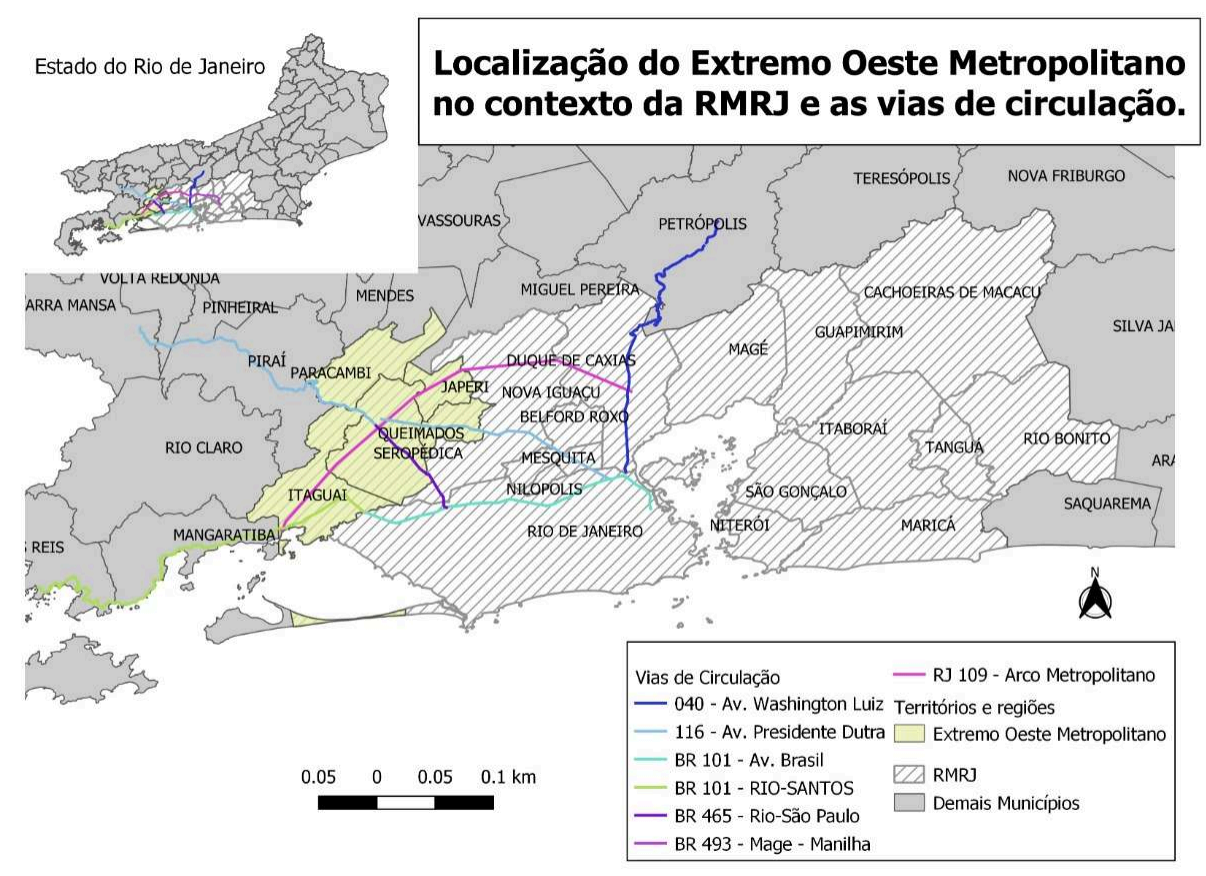

Fonte: IBGE 2020. Elaboração: LAGEP/UFRRJ. dessa sub-região, não podemos nos abster do fato de que esse conjunto de municípios está conectado à estrutura metropolitana e que essas transformações, de algum modo, ainda indicam elementos desta estrutura.

11 Para Abreu (2013, p. 18), ao longo do processo de formação da estrutura metropolitana do Rio de Janeiro, esses municípios se encontrariam numa confluência entre a transição da "periferia intermediária" [Queimados e Japeri] e parte da "periferia distante" [Seropédica, Itaguaí e Paracambi]. Essas concepções emergiram diante das transformações no contexto da segunda metade do século XX, sobretudo após os anos de 1970, mas também classificadas, respectivamente por Souza (2007) como "periferia e franja rural-urbana". (Figura 2 e 3 ). 
Figura 2. Região Metropolitana do Rio de Janeiro (1978) [com a sobreposição do que seria a área do extremo Oeste Metropolitano]

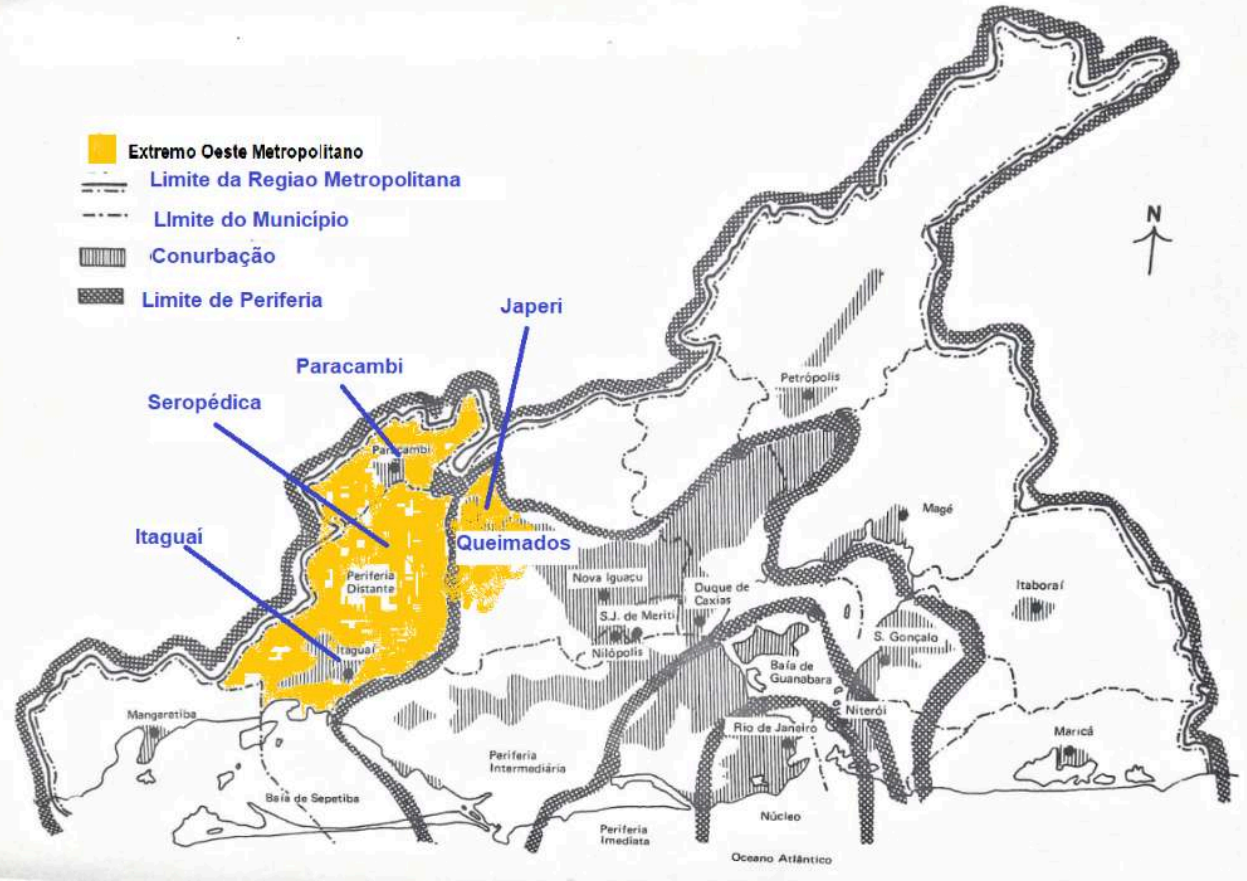

Fonte: ABREU, 2013, p.20 (modificado pelos Autores)

Figura 3 - Região Metropolitana do Rio de Janeiro: Classificação da organização espacial em grandes tipos segundo a dinâmica econômico-social [com inserção da área que seria o Extremo Oeste Metropolitano]

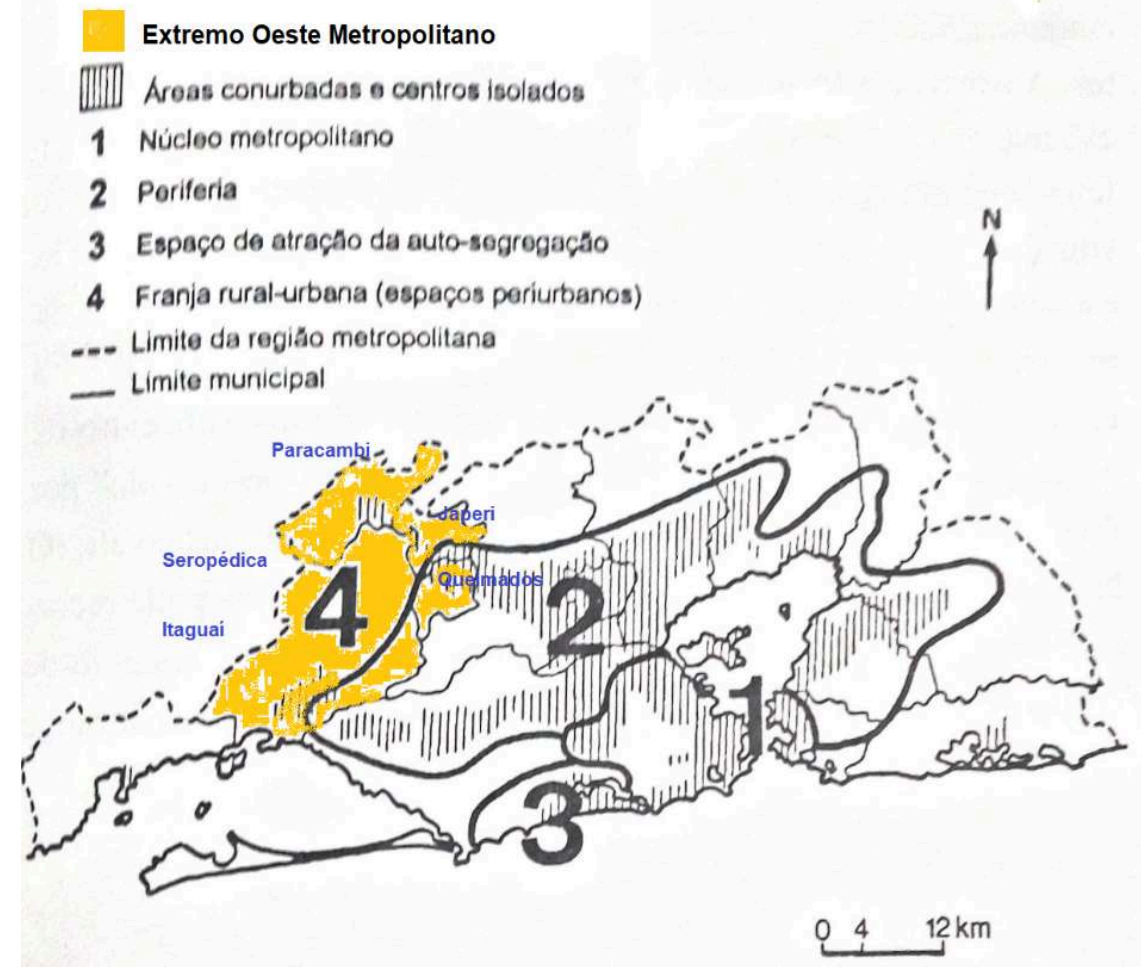

Fonte: Souza, 2007, p. 77. (Adaptado pelos autores) 
12 A periferia Intermediária consistiria na "área pela qual a metrópole se expande" (ABREU, 2013, p. 26). Essa "periferia intermediária” corresponderia aos municípios que apresentavam rápido crescimento populacional e intensas transformações urbanas, advindos das consolidações dos grandes loteamentos, das induções de urbanização nas proximidades das rodovias Avenida Presidente Dutra (BR-116) e Rodovia Washington Luiz (BR-040), e das marcas da interação da mobilidade urbana, em especial da "população mais pobre" (ibidem) que possui suas atividades laborais na cidade do Rio de Janeiro. Marcadamente, os municípios de Queimados e Japeri assumem em seus territórios essa posição, seja pela conectividade de integração da ferrovia, via ramal Central-Japeri e da passagem da BR-116, seja porque abarcam a história territorial do antigo município de Nova Iguaçu, considerado município-mãe ${ }^{2}$ e, portanto, acabam herdando dinâmicas de fluidez, mobilidade e centralidade articuladas a um eixo mais a leste. Há, portanto, uma forte conexão institucional política com a Baixada Fluminense (ROCHA, 2014; SIMÕES, 2007) e, conforme mencionamos em outro texto (ROCHA, 2015), o processo de reestruturação econômico-territorial em Queimados e Japeri é um acontecimento que se espraia a essas localidades pelas dinâmicas da metrópole.

13 Além disso, no final dos anos de 1990, Souza (2007) apresenta uma subdivisão que interpreta a maior parte destes municípios já como "periferia", porém, essa definição não estaria no certame dos limites municipais, mas numa linha tênue que se consolida nas formas dos usos sociais do espaços, que se materializariam os grandes loteamentos, apontados no processo de expansão urbana metropolitana que abarcaria toda a área que se conhece como Baixada Fluminense (SEGADAS SOARES, 1962; GEIGER E SANTOS, 1955), e também da presença de algumas glebas que seriam mantidas ociosas ou subutilizadas, claramente a espera de uma "especulação fundiária em grande escala" (SOUZA, 2007, p. 76).

14 Quanto à "periferia distante", que abarcaria os municípios de Itaguaí, Seropédica e Paracambi, mencionada por Abreu (para a temporalidade dos anos de 1970) se aproxima da indicação de Souza (2007, p. 77), que reporta, no contexto do anos 1990, esses municípios como parte de uma franja Rural-Urbana (espaço peri-urbano). Ao pensarmos na noção de "periferia distante", necessitamos entender que esses municípios nos anos de 1970 seriam aqueles menos integrados à estrutura metropolitana, no que tange às redes de transporte, e apresentariam menores densidades do tecido urbano. Por exemplo, embora Paracambi apresente uma ferrovia que a conecta a estação Central do Brasil, ela o faz por uma modulação até a estação de Japeri, da qual segue o caminho até a Central do Brasil. Assim, esse persiste numa dinâmica de integração no sentido a leste, tal como Japeri e Queimados. Já os municípios de Itaguaí e Seropédica estão conectados via interseções rodoviárias com a Avenida Brasil (BR-101) a partir da antiga estrada Rio-São Paulo (BR-465), que corta o município de Seropédica e a Reta de Piranema (RJ-099) que interliga áreas de Itaguaí até a BR-101 e a BR-465. Assim, a dinâmica de integração e conectividade das interações alcança um sentido sul e se espraia para áreas da Zona Oeste do Rio de Janeiro.

Em sua maioria, os espaços desses municípios entendidos como periurbanos, caracterizam uma zona de transição, onde os usos urbanos e rurais estariam presentes na paisagem (vista como aspecto visível), com menor grau de transformação, ainda com presença de atividades agropastoris (ALCANTARA, 2017), em sua maioria teriam a marca de um ar bucólico, dando aparência rural. Para Souza (2007, p. 26-27), nesta paisagem podem ser vistas: 
algumas plantações, muito verde, alguns espaços servindo de pastagem para algumas cabeça de gado - quando, na verdade, por trás disso se verifica uma presença insidiosa e cada vez mais forte da lógica urbana de uso do solo [Grifo nosso]

16 O entrelaçamento entre a realidade urbana e rural, sobretudo na formação de uma "reserva de uso potencial do solo", é usado como estratégia para incorporação do mesmo como mercadoria para momentos oportunos. É interessante frisar que, nos anos 2000 e 2010, essa nova lógica de uso e apropriação do solo se tornou um dos pilares do fomento das grandes transformações da reestruturação territorial-produtiva, o que demandaria a essa região novos usos do espaço postos na atratividade econômica de condomínio logístico e atividades fabris. Esse argumento foi recorrentemente utilizado pela Federação das Indústrias do Rio de Janeiro (FIRJAN) para fomentar o desenvolvimento e apropriação territorial desta região (ROCHA, 2014). Outrossim, não se pode ignorar o quanto essa área é atualmente eleita para ser uma região de sacrifício ambiental.

17 Ao passo que entendemos uma reestruturação territorial-produtiva desencadeada no contexto entre os anos 2000 e 2010 para esta área, a concebemos também como uma importante redefinição da estrutura metropolitana. Ao tentar compreender processos que interligariam esses municípios da "periferia distante" (Itaguaí, Paracambi e Seropédica) e da "periferia intermediária" (Queimados e Japeri), quando pensadas no atual contexto, se torna nítido como as mudanças empreendidas com os novos usos do solo para atratividades de dinâmicas fabris e imobiliárias, valorizadas pela dimensão logística, estão alicerçadas na possibilidade de especulação fundiária destas áreas com "terras disponíveis". Essa nova dinâmica econômica no contexto maior da metrópole, produz centralidades e interações e, portanto, redefinem a estrutura metropolitana no Rio de Janeiro.

Neste sentido, a regionalização do Extremo Oeste Metropolitano, que visava entender dinâmicas de convergências e linkagens econômicas que se estabelecem entre a Metrópole e seu interior (OLIVEIRA, 2015), quando observada no conjunto das interações espaciais, constitui a oportunidade de visualização do transbordamento das novas dinâmicas da metrópole. Ela viabiliza interpretações de novas lógicas de usos e processos em parte de região metropolitana, diante das fortes reverberações nas estruturas da Zona Oeste do Rio de Janeiro e das regiões do Sul e Centro Sul Fluminense.

19 A estrutura metropolitana se redesenha! Uma vez que essas classificações dos anos de 1970 e 1990 necessitam ser repensadas, não como negação das mesmas, mas como elementos para uma regionalização desta área que permita pensar interações espaciais. Uma vez que entendemos que há, atualmente, uma expansão da periferia direta e a incorporação gradativa deste periurbano a este uso. Perceberemos que, quando observamos as lógicas de interações dadas pelo fluxo dos trabalhadores em seu movimento pendular, o Extremo Oeste Metropolitano revela sentidos de conectividade e interação que indicam o quanto esses municípios foram incorporados à dinâmica da centralidade da metrópole do Rio de Janeiro e que passou a expressar outras centralidades que permitem a incorporação e expansão gradativa desta periferia direta com maior densidade de transformação urbana.

20 Neste sentido, pensar a mobilidade do trabalhador se torna relevante, para entender as lógicas de conexão com a estrutura metropolitana e suas contínuas transformações. 


\section{Teorias e aportes para análise da Mobilidade do Trabalhador (movimento pendular)}

21 A análise da mobilidade pendular remete ao estudo das aglomerações urbanas e suas interações espaciais. $O$ crescimento acelerado das metrópoles brasileiras, associado ao aumento do custo de vida em suas áreas centrais, acabou por direcionar novas lógicas de ocupação dos espaços periféricos, aumentando a dimensão e a complexidade da divisão social e territorial do trabalho, com forte segmentação e fragmentação dos tecidos urbanos. Assim, a análise da redefinição da metrópole possibilita a compreensão dos novos arranjos espaciais, onde a mobilidade populacional aparece como um dos elementos definidores do espaço urbano cotidiano. Cunha et al. (2013) faz um breve levantamento de estudos que apresentam a relação direta que se estabelece entre a mobilidade pendular e o desenvolvimento de áreas urbanas.

Esse modelo de ocupação do território alimenta um desencontro entre as áreas de trabalho e de moradia da população, aumentando a necessidade do deslocamento diário casa-trabalho. Para Aranha (2005), as desigualdades socioespaciais seriam a base explicativa da existência dessa mobilidade. Moura et al. (2005) se remetem a esses movimentos como um fenômeno não apenas que representa as desigualdades, mas também como um meio para a compreensão dos resultados da reestruturação do espaço metropolitano. Baeninger (2004) considera que a mobilidade pendular é em boa parte reflexo do processo de expansão urbana e suas tendências de concentrar as possibilidades de emprego com lógica distinta daquela com que se criam as possibilidades de moradia, gerando grandes dificuldades e descompassos entre as duas categorias de localização espacial. De qualquer modo, a possibilidade de mover-se no espaço intraurbano, incrementada pela melhoria ou maior oferta de transportes (mesmo que nem sempre em condições adequadas), implica para os indivíduos e/ou famílias em estratégias para a reprodução social (Cunha e Sobreira, 2008). (CUNHA et al., 2013, p. 440)

Desta maneira, os arranjos espaciais da metrópole seguem uma nova orientação, possibilitada pela dinâmica dos grupos sociais que se deslocam cotidianamente para realizar funções de trabalho, estudo e lazer fora de seu município de residência. A análise dos deslocamentos pendulares possibilita compreender que o espaço tem um valor próprio, definido pelo trabalho social e valorizado pela sua localização. Santos (1987, p. 81), discutindo sobre a importância da localização geográfica, avalia que "pessoas com a mesma virtualidade, têm valor diferente segundo o lugar em que vivem: as oportunidades não são as mesmas. Por isso, a possibilidade de ser mais ou menos cidadão depende, em larga proporção, do ponto do território onde se está".

23 A análise da mobilidade pendular, portanto, permite entender a lógica de produção e apropriação do espaço urbano e, amparados pelos estudos de Castello Branco, Firkowski e Moura (2005), Jardim e Ervatti (2006), Cunha (1995), reafirmamos que a mobilidade pendular está relacionada à expansão das aglomerações urbanas, "uma vez que reflete o descompasso entre o processo de redistribuição da população e a distribuição das atividades econômicas e de serviços no espaço urbano", evidenciando as interações espaciais que ali existem.

Neste sentido, Jardim (2005, p. 383) afirma ainda que:

O deslocamento da população no espaço metropolitano reflete a estrutura econômica e social desse espaço, assim como as condições desses deslocamentos, indicando novos arranjos sociais e econômicos, conformando novos espaços existenciais. Novas áreas são incorporadas à metrópole, novos rearranjos familiares 
e demográficos se estabelecem a partir de certas condições socioeconômicas. Portanto, novas formas espaciais e temporais são estabelecidas a partir da mobilidade da população. São as novas formas existenciais que tornam visíveis os processos de exclusão/inclusão, segregação, "enobrecimento de novas áreas residenciais" ("gentrificação") e de pobreza, entre outros fenômenos sociais existentes na atual fase de desenvolvimento do capitalismo

As interações espaciais desenvolvidas a partir do deslocamento de pessoas em áreas metropolitanas contribuem no estabelecimento das diferenças sócio-espaciais e permitem a identificação de processos seletivos de uso e apropriação do espaço, com segmentação dos locais de moradia e de trabalho (CASTELLO BRANCO, FIRKOWSKI e MOURA, 2005). Assim, os deslocamentos intra-metropolitanos podem ser analisados a partir da concepção da mobilidade da força do trabalho, conceito desenvolvido por Gaudemar (1977), onde entendemos que os deslocamentos ocorrem numa relação dialética entre fenômenos de ordem social e econômica, configurando movimentos criados e dinamizados pelo sistema capitalista, mas que, por sua vez, também agilizam e ampliam o grau de complexidade das contradições e redefinem espaços e territórios.

Conquanto as migrações de mão-de-obra periódica estejam declinando quase em toda parte, os movimentos diários estão constantemente aumentando quer em número quer em distância; esses dois fatos são apenas duas manifestações da influência do progresso técnico sobre a vida e a atividade humanas. Os modernos meios de transporte estão favorecendo o que se tornou necessidade econômica, isto é, a concentração dos meios de produção e o crescimento das cidades. (BEAUJEUGARNIER, 1980, p. 292)

Embora Beaujeu-Garnier (1980) esteja analisando os movimentos populacionais da década de 1970, ela aponta para a importância dos deslocamentos internos pendulares e sua complexa e dinâmica relação com crescimento urbano das cidades. Entendemos que esta é uma situação que permanece atual - os moradores das periferias ainda necessitam se deslocar para os centros metropolitanos em busca de melhores condições de trabalho, devido à reprodução da desigualdade e fragmentação do tecido urbano. Muitos países, como Estados Unidos, França e Inglaterra baseiam seus estudos sobre deslocamentos pendulares por motivo de trabalho e suas interações espaciais entre as cidades, para definir e entender as aglomerações urbanas e áreas metropolitanas. Segundo Castello Branco, Firkowski e Moura (2005), a pesquisa sobre movimento pendular foi introduzida no Censo Demográfico de 1970, buscando obter informações sobre a proporção de população residente que trabalhava fora do município; o Censo de 1980 privilegiou as regiões metropolitanas, não captando o movimento pendular que ocorre da periferia para o núcleo; no Censo de 1991 não se contemplou na pesquisa o movimento pendular. Já no Censo de 2000 o quesito foi reintroduzido, pesquisando-se para a população residente o município de origem e destino para trabalho e estudo, onde puderam ser identificadas aglomerações que apresentavam predominância dos fluxos do entorno para o polo (CASTELLO BRANCO, FIRKOWSKI e MOURA, 2005, p. 8). No Censo de 2010 algumas concepções sobre o deslocamento pendular foram novamente verificadas, onde foram analisados o tempo de deslocamento entre o trabalho e local de moradia, sendo o Rio de Janeiro o estado onde as pessoas demoram mais tempo nos trajetos casa-trabalho, sendo este muitas vezes superior a duas horas.

Através do Censo Demográfico de 2010, pudemos observar que houve um decréscimo populacional das áreas metropolitanas; no entanto, verificamos que os deslocamentos pendulares e o fluxo intrametropolitano ainda é considerado bastante expressivo. E, ainda, com o processo de reestruturação econômica que ocorre na Baixada Fluminense, 
novas áreas com potencial de centralidade, articulação e infraestrutura passaram a também configurar núcleos de atração para a dinâmica da mobilidade populacional de seus municípios vizinhos. Entendemos que esta reestruturação aplicada à totalidade da metrópole implica em mudanças que podem ser percebidas na sub-região do Extremo Oeste Metropolitano, uma vez que se amplia em quantidade e qualidade as suas relações, internas e externas pela proximidade e possibilidade de articulação e conexão existente nela.

De acordo com Silva (2009) e Silva (2017), o processo de reestruturação urbana e das cidades, atrelado às novas demandas da reprodução capitalista, intensificam estes processos e levam a uma movimentação espacial dos capitais que reorientam as práticas urbanas cotidianas, bem como os vetores de expansão e valorização. Isto posto, o par centro e periferia é ressignificado, com novas dimensões e padrões de uma mobilidade e rotatividade urbana. Então, algumas cidades até então localizadas na periferia da rede urbana, passam a receber investimentos e a se tornarem lócus privilegiados de reprodução de capitais, o que reestrutura suas organizações internas.

Neste sentido, compreendemos que com o crescimento das periferias imediatas ao núcleo da metrópole e seu consequente desenvolvimento devido à reestruturação econômica que se manifesta nesta área, outras cidades passaram a exercer uma certa centralidade periférica para os municípios adjacentes evidenciando uma região mais complexa, com expressivas diferenças espaciais e contradições sociais, porém, bastante dinâmica e articulada.

\section{Deslocamentos dos trabalhadores e interações espaciais dos Municípios do Extremo Oeste Metropolitano}

30 Ao passo que entendemos o Extremo Oeste Metropolitano (EOM) como uma mesoescala para interpretar a estrutura da região metropolitana em um contexto de reestruturação territorial produtiva e, que a compreensão das interações produzidas pela mobilidade do trabalhador está intimamente articulada com essa mesma estrutura metropolitana e suas dinâmicas socioespaciais, apontaremos a partir dos dados que serão elencados que tal interação, revela na prática, a expansão territorial da uma periferia direta. Ou seja. O EOM passa a se integrar cada vez na dinâmica que antes eram percebidas na periferia direta, ou seja municípios mais próximo do núcleo metropolitano.

31 Os dados do Censo de 2010, servem como elementos indicadores para especializarmos essa dinâmica de interação, que vai indicando processos de constituição de centralidades e vetores de integração, bem como definindo bem os papéis de algumas cidades no contexto metropolitano. (Figura 4). 
Figura 4 - Mapa da mobilidade a partir da saída do morador do extremo oeste metropolitano para outros municípios.

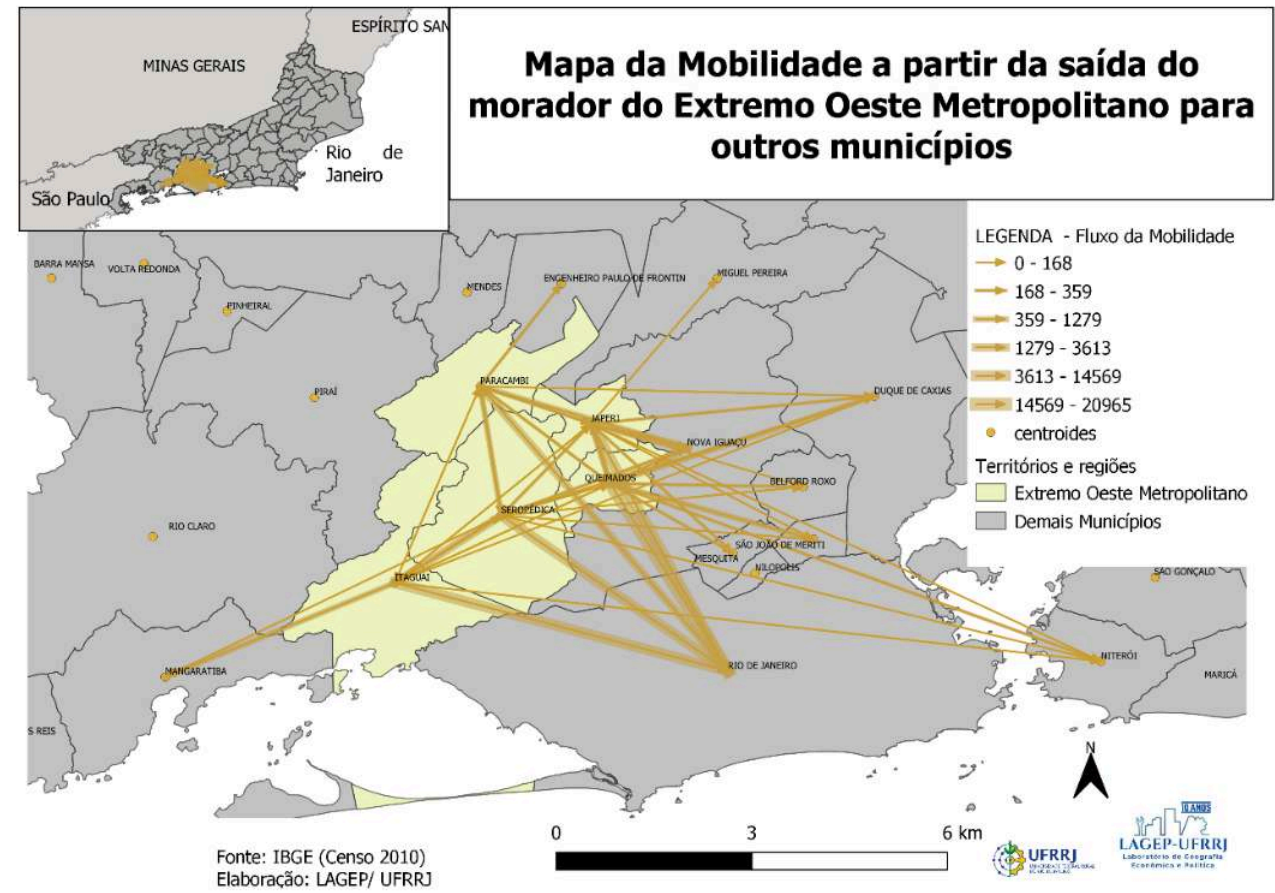

Fonte: IBGE 2010. Elaboração: LAGEP/UFRRJ.

A figura 4 indica, a partir dos dados sobre a mobilidade do morador oriundo dos municípios do Extremo Oeste Metropolitano, que esses municípios estão em conectividade com diversos outros da região metropolitana. Além disso, indica o extravasamento de interações com municípios vizinhos, como Mangaratiba, Engenheiro Paulo de Frontin e Miguel Pereira.

33 É perceptível uma maior densidade dos fluxos ainda em direção à cidade do Rio de Janeiro, porém, há uma significativa trama desta rede em direção a outros municípios da Região Metropolitana do Rio de Janeiro, que reverbera na consolidação das centralidades de Municípios como Nova Iguaçu e Duque de Caxias. Também é perceptível uma densidade de fluxo que consolida Itaguaí como uma centralidade nesta sub-região.

34 A direção destes fluxos em termos proporcionais de deslocamento deixa isso bem evidente quando observados os perfis individuais do destino dos trabalhadores de cada município. (Figuras 5 e 6 ). 
Figura 5- Mapa do perfil individual do Fluxo de destino dos Trabalhadores do Extremo Oeste Metropolitano

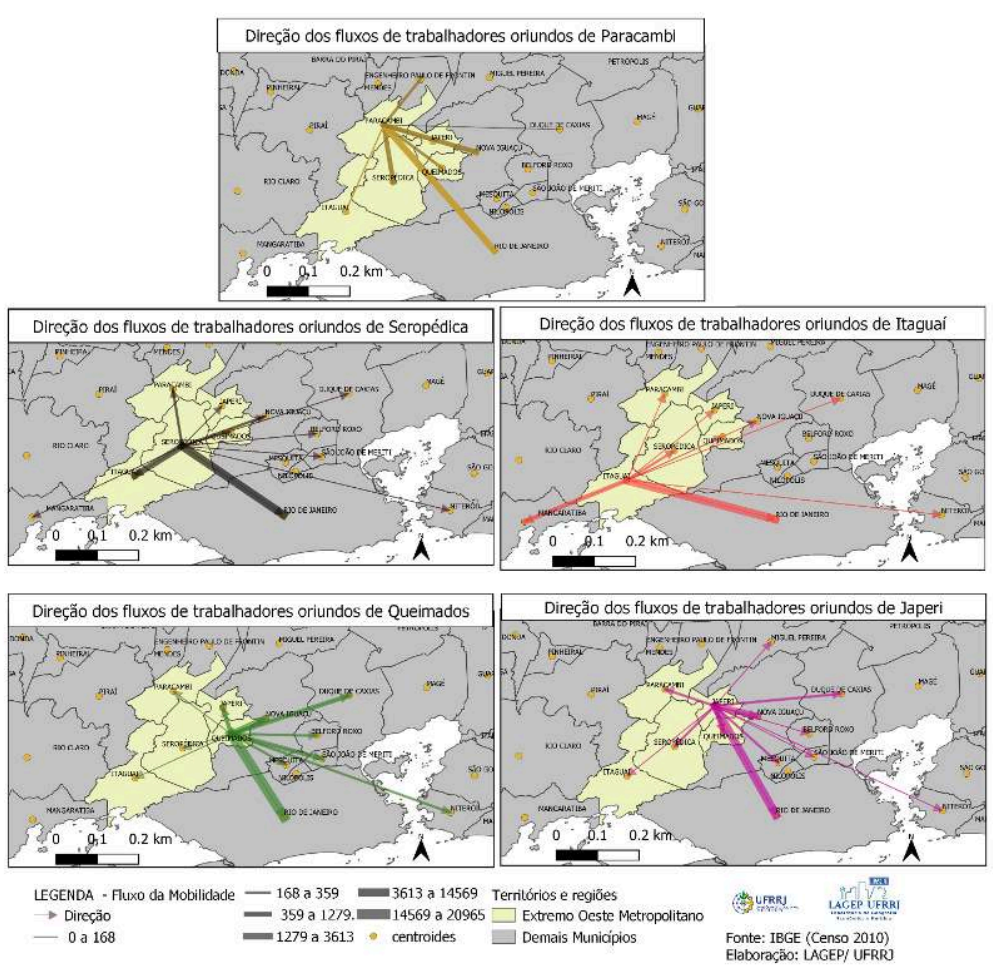

Fonte: IBGE 2010. Elaboração: LAGEP/UFRRJ

Figura 6 - Quadro comparativo do percentual de origem destino dos trabalhadores do Extremo Oeste Metropolitano - 2010

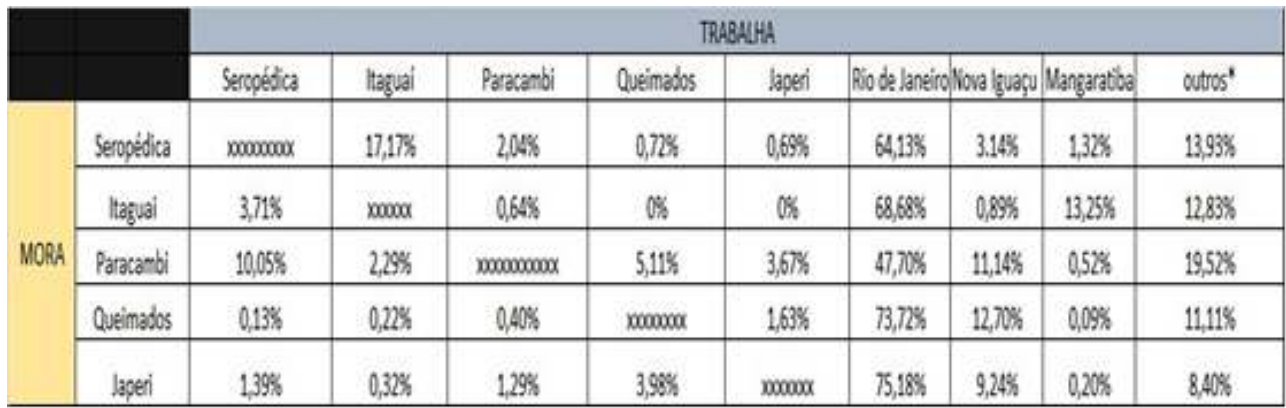

Fonte: IBGE (2010). Elaboração dos Autores. *Demais municípios da Região Metropolitana do Rio de Janeiro, mais os municípios de Mangaratiba, Miguel Pereira, Rio Claro e Engenheiro Paulo de Frontin e Teresópolis.

Os mapas contidos na figura 5 revelam a espacialização dos fluxos populacionais do Extremo Oeste Metropolitano (EOM), em que é possível identificar que, embora exista uma pequena interação de fluxos entre esses municípios, ainda se verifica predomínio da atratividade do Município do Rio de Janeiro, o que depreende-se como reflexos da histórica estrutura metropolitana. Esse fato revela que, mesmo com a transformação espacial e econômica experimentada no interior da região metropolitana e da consolidação de novas centralidades, o Rio de Janeiro ainda possui grande influência na de oferta de trabalho. A dinâmica da Cidade do Rio de Janeiro revela uma expressiva atratividade da Área Central, contudo, também se verifica a expressão de centralidades 
importantes na Barra da Tijuca e porções da Zona Oeste, além das tradicionais áreas da Zonas Sul. Assim, o trabalhador em mobilidade pendular reproduz a lógica dos capitais seguindo a reestruturação da economia metropolitana, e Corrêa (2005) colabora afirmando que "estabelece-se uma crescente divisão territorial do trabalho que leva a uma necessária articulação entre áreas e cidades através de uma rede urbana cada vez mais importante e fortemente articulada" (CORREA, 2005, p. 282). Percebemos, assim, a relação direta que se estabelece entre a rede urbana e rotina do trabalhador que se evidencia, muitas vezes, pelos deslocamentos cotidianos destes entre os munícipios.

Os dados presentes da na figura 6 revelam que em média mais de $65 \%$ dos fluxos do EOM se destinam ao Município do Rio de Janeiro, chegando a taxas de $75,18 \%$, se pensados os fluxos oriundos de Japeri. Essa dinâmica de interação reforça que os ritmos de desigualdade na distribuição espacial metropolitana e da concentração de serviços pode demandar grandes impactos no tempo de deslocamento do transporte dessas populações. É por isso que foi identificado que as pesquisas realizadas pelo IBGE destacam que Japeri é o município do Brasil que o trabalhador leva mais tempo para chegar em casa. ${ }^{3}$ Em média, moradores de Japeri levam duas horas no deslocamento casa-trabalho. Queimados é considerado o segundo do país e Seropédica está em nono lugar no ranking dos dez piores municípios em deslocamento diário. Porém, isso não é apenas para os municípios do EOM, estão também incluídos Nova Iguaçu (4 lugar), Magé ( $6^{\circ}$ lugar) e Belford Roxo ( $8^{\circ}$ Lugar), localizados na Baixada Fluminense. Este fato, remete à necessidade de viabilização de políticas públicas que priorizem investimentos em infraestruturas de acessibilidade e transportes. Via de regra, os investimentos realizados nestes setores priorizam o circuito superior da economia, no entanto, este só pode ser movimentado por meio dos seus trabalhadores. Vasconcellos (2000) contribui com nossa análise ao afirmar que "O transporte é um serviço vital para qualquer sociedade. Ele assegura o direito à comunicação, integra o espaço $e$ as atividades e é essencial para a economia" (VASCONCELLOS, 2000, p. 195). Assim, só poderíamos pensar em uma rede urbana fortemente integrada através de uma economia dinâmica e com fácil acessibilidade através dos transportes

Todavia, a partir da leitura e interpretação das figuras 5 e 6, é possível identificar que existe uma dinâmica expressiva que valoriza dois vetores, que chamaremos de vetores leste e sul.

O vetor leste compreende os fluxos que se direcionam em sua maioria para o município de Nova Iguaçu. Essa direção apresenta a herança da estrutura territorial e urbana que consolida municípios como Queimados, Paracambi e Japeri, como fortemente influenciados pela dinâmica da centralidade econômico-produtiva iguaçuana. Nova Iguaçu absorve significativas parcelas dos fluxos, sendo Queimados $12,70 \%$, Paracambi $11,14 \%$ e Japeri $9,24 \%$. Como nos lembra Lago (2007), Nova Iguaçu se consolida como um centro de comércio e serviços, mostrando que a "periferia é um lugar de trabalho". Ainda, reforça-se o fato de que, embora exista um parque industrial no município de Queimados, sua dinâmica ainda não é suficiente para atratividade significativa dos trabalhadores dos demais municípios, seja pela baixa qualificação da mão de obra residente nos municípios do EOM, seja pela demanda em outras atividades de forte atração de outros centros. Reforça-se, também, o fato de que o processo de reestruturação econômica e urbana da metrópole reverberou em consolidar a centralidade de Nova Iguaçu, que já estava inserida como uma "periferia consolidada", e que recebeu, por exemplo, os maiores fluxos de investimentos em novos 
empreendimentos imobiliários, juntamente com Itaguaí e a cidade do Rio de Janeiro, no contexto da reestruturação territorial experimentada na região metropolitana (ROCHA, 2015).

Percebemos, então, que o espaço urbano, mesmo com um processo de fragmentação, possui correlações diretas entre as diversas áreas, sendo as mesmas complementares e concorrentes, simultaneamente, fato que possibilita e reforça a segregação urbana, que separa e distancia os diferentes segmentos que integram o espaço urbano; desta forma, os deslocamentos pendulares estão relacionados à estrutura do modo capitalista de produção, que é seletivo e excludente, e faz com que o espaço urbano seja produzido coletivamente, porém, apropriado seletivamente (MELCHIOR, 2020).

$O$ vetor que chamaremos Sul revela o eixo de deslocamento no sentido Paracambi, Seropédica, Itaguaí. Este é o eixo no qual os fluxos revelam significativo volume de interações, onde encontram 10,05\% dos fluxos de Paracambi para Seropédica, e expressivos $17,17 \%$ dos fluxos de Seropédica para Itaguaí. Estes dados podem ser exemplificados pelo fato de que Itaguaí se consolida como subcentralidade nesta região, com forte influência nos serviços e oferta do emprego, em especial com grande influência sobre Seropédica. Também, verificamos tímida influência sobre Paracambi, uma vez que que recebe cerca de $3,71 \%$ dos fluxos de trabalho. Esta influência acontece tanto pela atividade fabril e dinâmica reverberada pela dinamização do porto de Itaguaí, quanto por uma estrutura pretérita de centralidade municipal, uma vez que o Município de Seropédica foi desmembrado de Itaguaí em 1995. Assim, Itaguaí ainda congrega muitos serviços públicos e privados que influenciam a dinâmica da cidade vizinha. Por sua vez, Seropédica apresenta uma grande concentração de atratividade nas estruturas dos serviços públicos, marcadamente pela presença da Embrapa e da Universidade Federal Rural do Rio de Janeiro (UFRRJ), que servem como importantes canais empregadores no município, juntamente com a prefeitura municipal. Um aspecto a ser considerado é o extravasamento de interações para além da região metropolitana, com destaque para Mangaratiba, que recebe 13,25\% dos fluxos oriundos de Itaguaí; isso destaca tanto as interações por proximidade espacial quanto um transbordamento das dinâmicas metropolitanas que avançam sobre a sul fluminense

Com isso, vemos novas configurações espaciais sendo apresentadas, com expressivas lógicas e investimentos do capital redefinindo novas centralidades e direcionamentos da classe trabalhadora, porém reforçam as diferenças e as segregações sócio-espaciais dificultando que o trabalhador tenha maior possiblidade de vivenciar seu território por conta do desgaste massivo com os deslocamentos (MELCHIOR, 2020).

\section{Considerações finais}

42 As novas dinâmicas produtivas empreenderam modificações na estrutura da região metropolitana do Rio de Janeiro, dentre as quais, é possível entender a expansão mais nítida de uma "periferia direta", que por sua vez incorpora os municípios do EOM, que antes estavam numa zona de transição que foi identificada como uma "periferia distante" e "periferia intermediária", sob signo de um espaço "periurbano".

Essas transformações serviram para elucidar o quanto o "periurbano" é uma dimensão especulativa que se entrelaça com a dinâmica da renda da terra e da especulação fundiária que servem como "reserva" para expansão de atividades existentes do urbano. A reestruturação territorial produtiva é também fortemente articulada com a 
dinâmica de especulação da terra, que amplia a estrutura metropolitana da periferia para abarcar as novas atividades imobiliárias e industriais. Como apresentado, a partir dos dados de fluxos populacionais de 2010, embora existam modificações de algumas estruturas, há a consolidação de centralidades como Nova Iguaçu e Itaguaí. Os fluxos de interação, revelam que as áreas do EOM estão cada vez mais integradas aos processos metropolitanos, cujas interações constituem uma rede densa e com indicativos de modificações.

Assim, o EOM pode ser visto como uma sub-região com pequeno grau de interação interna, mas que está conectada com a dinâmica da metrópole. Sua coesão está mais na forma singular que estes municípios são aderidos à metropolização, advindas das expectativas de desenvolvimento do Estado do Rio de Janeiro, do que por sua interação de fluxos de deslocamentos e integração territorial, embora possa já estar indicando traços significativos de interação, sobretudo a partir do vetor sul - ParacambiSeropédica e Itaguaí.

Por fim, compreendemos a necessidade de reforçar o papel dos estudos das interações que envolvem a mobilidade populacional intrametropolitana, uma vez que estes estão fortemente conectados com uma geografia desigual de distribuição de atividades produtivas, ofertas de serviços e de lazer, e que a compreensão das transformações espaciais metropolitanas não pode ignorar as interações como elemento analítico.

Portanto, a mobilidade dos trabalhadores que se deslocam cotidianamente entre os munícipios da região metropolitana reforça e possibilita a melhor compreensão dos vetores que impulsionam a reestruturação econômica da metrópole. Num mundo pautado pela ordem capitalista, onde o trabalho é constantemente subjugado e se mobiliza de acordo com as demandas capitalistas, a mobilidade pendular reflete as necessidades desta nova configuração, onde os trabalhadores passam a viver em áreas mais periféricas, expandindo territorialmente a metrópole, mas sua força de trabalho é demandada nas áreas que estão realizando processos de reestruturação.

\section{BIBLIOGRAFIA}

ABREU, M. Evolução Urbana do Rio de Janeiro. 4⿳⺈冂ed. Rio de Janeiro: IPP, 2013.

ALCANTARA, Denise de. Oficinas de Intervenções Urbanas na periferia metropolitana: ressignificando espaços livres públicos pela extensão. CADERNOS PROARQ (UFRJ), v. 29, p. 29-44, 2017. Disponível em < https://cadernos.proarq.fau.ufrj.br/public/docs/ Proarq29\%20ART\%2002.pdf>. Acesso em 15 de ago. 2020.

BEAUJEU-GARNIER, J. Geografia da população. São Paulo: Companhia Editora Nacional, 1980.

CASTELLO BRANCO, Maria Luiza, FIRKOWSKI, Olga Lúcia C. de Freitas e MOURA, Rosa. Movimento pendular: abordagem teórica e reflexões sobre o uso do indicador. In: Anais do XI Encontro Nacional da associação nacional de Pós-graduação e pesquisa em planejamento urbano e regional - ANPUR, Salvador/BA, 2005 
Movimento pendular e perspectivas de pesquisas em aglomerados urbanos. In: Revista São Paulo em perspectiva. São Paulo-SP. V.19. n.4, 2005

CORRÊA, R. L. Trajetórias Geográficas. Rio de Janeiro: Bertrand Brasil, 2005. Interações Espaciais. In: CASTRO, Iná Elias de; GOMES, Paulo Cesar da Costa da; CORRÊA, Roberto Lobato. Explorações Geográficas. Rio de Janeiro. 1997. Bertrand Brasil. Região e organização espacial. Ática: São Paulo, 1993.

CUNHA, J. M. et al. A mobilidade pendular na Macrometrópole Paulista: diferenciação e complementaridade socioespacial. In: Cadernos Metrópoles. São Paulo. V.15. n.30, 2013.

CUNHA, José Marcos Pinto. A mobilidade intra-regional na metrópole: consolida-se uma questão. In: Revista Travessia. São Paulo, Ano VIII, nº 23, Set/Dez - 1995

GAUDEMAR, J. P.. Mobilidade do trabalho e acumulação do capital. Lisboa: Editora Stampa, 1977.

GEIGER, P.P; SANTOS, R.L. Notas sobre a evolução da ocupação urbana da Baixada Fluminense. Revista Brasileira de Geografia. Rio de Janeiro, n3, ano 16, jul/set, 1955.

JARDIM, Antonio de Ponte e ERVATTI, Leila Regina Migração pendular intrametropolitana no Rio de Janeiro: a condição de renda das pessoas que trabalham ou estudam fora do município de residência em 1980 e 2000. In: Anais do XVI Encontro Nacional de Estudos Populacionais, Caxambu-MG, 2006

JARDIM, Antonio de Ponte. Mobilidade intrametropolitana no Rio de Janeiro. In: PÓVOA-NETO, Helion, FERREIRA, Ademir Pacelli (orgs). Cruzando fronteiras disciplinares: um panorama dos estudos migratórios. Rio de Janeiro: Revan, 2005

HAESBAERT, R. Morte e vida da Região. Antigos paradigmas e novas perspectivas da geografia regional. IN: SPOSITO, E.S. A produção do espaço e redefinições regionais: a construção de uma temática. Presidente Prudente/SP: UNESP/FCT/GAsPERR, 2005. pp.9-34.

LAGO, L. C. A "periferia" metropolitana como lugar do trabalho: da cidade-dormitório à cidade plena. In: Cadernos IPPUR/UFRJ/Instituto de Pesquisa e Planejamento Urbano e Regional da Universidade Federal do Rio de Janeiro. Ano XXI, no 2, p. 9 - 28, ago-dez 2007

MELCHIOR, L. Mobilidade pendular e reestruturação metropolitana do Rio de Janeiro. In: Maia, D. S., RODRIGUES, A. M., SILVA, W. R. Expansão Urbana. João Pessoa: EDUFPB, 2020. (No Prelo).

OLIVEIRA, F. J. G.; OLIVEIRA, L. D. Espaço metropolitano, regionalização da economia e reestruturação produtiva no estado do Rio de Janeiro - Brasil. Cuyonomics: Investigaciones en Economía Regional, v. 3, p. 39-65, 2020.

OLIVEIRA, L. D. A emersão da região logístico-industrial do Extremo Oeste Metropolitano fluminense: reflexões sobre o processo contemporâneo de reestruturação territorial-produtiva, Espaço e Economia [Online], 7 | 2015. Disponível em http://journals.openedition.org/ espacoeconomia/1814; DOI : 10.4000/espacoeconomia.1814

ROCHA, A.S. Os efeitos da reestruturação econômica metropolitana na Baixada Fluminense: Apontamentos sobre o "novo" mercado imobiliário da região. Espaço e Economia. Espaço e Economia, Ano 3, n.o 6, Janeiro / Junho de 2015. Disponível em:http://espacoeconomia.revues.org/ 1677. Acesso em: 10 de dezembro de 2015.

DOI : $10.4000 /$ espacoeconomia.1677

ROCHA, A.S. "As representações ideais de um território" - Dinâmica econômica e política, agentes e a produção de novos sentidos na apropriação territorial da Baixada Fluminense pós 1990. PPGG / IGEO- UFRJ. (Tese de Doutorado), 2014 
SANTOS, M. A natureza do Espaço. São Paulo: Edusp, 2002.

O espaço do cidadão. São Paulo: Nobel, 1987.

SEGADA SOARES, M. T. Nova Iguaçu: absorção de uma célula urbana pelo Grande Rio de Janeiro. In: Revista Brasileira de Geografia. Rio de Janeiro: IBGE, vol2, n24, p.155-256, 1962.

SILVA, M. R. Palmilhando periferias da metrópole do Rio de Janeiro: o corpo e o valor nas formas desdobradas dos territórios de contenção. In: André Santos da Rocha. (Org.). Baixada Fluminense: estudos contemporâneos e (re)descobertas histórico-geográficas. 1ed.Duque de Caxias, RJ: ASAMIH, 2020 , v. 1, p. 26-61.

SILVA, W. R. Centralidade, shopping centers e reestruturação das cidades médias. In: MAIA, Doralice Sátyro; SILVA, William Ribeiro da; WITHACKER, Arthur Magon. (Orgs.). Centro e Centralidade em Cidades Médias. 1ed. São Paulo: UNESP - Cultura Acadêmica, 2017, v. 1, p. 199-226.

SILVA, W. R. O papel das cidades médias diante da reestruturação urbana. In: BICALHO, Ana Maria de Melo Souza; GOMES, Paulo Cesar da Costa. (Org.). Questões Metodológicas e Novas Temáticas na Pesquisa Geográfica. 1ed. Rio de Janeiro: Publit, 2009, v. 1, p. 125-140.

SOUZA, M.L. ABC do Desenvolvimento Urbano.3ª Ed. Rio de Janeiro, 2007.

SIMÕES, M. R. A cidade Estilhaçada - reestruturação econômica e emancipações municipais na Baixada Fluminense. Mesquita: Entorno, 2007.

THRIFT, N. Visando o âmago da região. In: GREGORY, Derek et all (org's). Geografia Humana. Sociedade, espaço e ciência social. Rio de Janeiro: Zahar, 1996.

VASCONCELLOS, Eduardo Alcântara. Transporte urbano nos países em desenvolvimento: reflexões e propostas. 3. Ed - São Paulo: Annablume, 2000.

\section{NOTAS}

1. As subdivisões internas na região metropolitana que mencionamos tem origem em diversos trabalhos que buscam definir essas à Capital - que se caracteriza pelo Município do Rio de Janeiro; o Leste-Metropolitano, que se capilarizou pela centralidade de Niterói e ganhou notoriedade nos últimos anos devido aos processos envolvidos na construção do COMPERJ; A Baixada Fluminense - subdivisão cuja identidade é marcada pelo estigma da violência e apresenta novas dinâmicas econômicas com centralidades em Nova Iguaçu e Duque de Caxias; o Extremo Oeste Metropolitano - conjunto de municípios que localizados a oeste, como extensão da Baixada Fluminense, mas que experimentaram uma reestruturação-territorial produtiva oriunda da revitalização do porto de Itaguaí e da condição logística imposta pela seção final do Arco metropolitano. (OLIVEIRA, F; OLIVEIRA, L., 2020; ROCHA, 2015; OLIVEIRA, 2015; SOUZA, 2007).

2. Vale reforçar que Queimados e Japeri eram parte do território de Iguaçu e foram emancipados somente nos anos de 1990.

3. Ver por exemplo reportagem < http://g1.globo.com/rio-de-janeiro/noticia/2012/04/ japeri-rj-e-cidade-do-pais-com-mais-demora-para-chegar-ao-trabalho.html> 


\section{RESUMOS}

Apresentamos com este texto uma discussão sobre a reestruturação metropolitana e suas significativas mudanças nos arranjos espaciais regionais. Temos como recorte territorial a subregião do Extremo Oeste Metropolitano (EOM) da Região Metropolitana do Rio de Janeiro, em que, através de análises do deslocamento pendular de trabalhadores, identificamos que, além das fortes e históricas interações com o núcleo metropolitano há, também, importantes interações entre os municípios analisados. Evidenciamos que a estrutura metropolitana é a norteadora dos investimentos dos capitais que se reproduzem na região e que o EOM desempenha papéis dentro da divisão metropolitana do trabalho de maneira mais complexa do que a identificada nas décadas passadas.

This article presents a discussion on the metropolitan restructuring and its significant changes in the regional spatial arrangements. Our territorial section is the sub-region of the Metropolitan Extreme West (EOM) of the Metropolitan Region of Rio de Janeiro, in which, analyses of workers pendulum mobility, we identified that in addition to the strong and historical interactions with the metropolitan nucleus there are also important interactions between the municipalities analyzed. The study demonstrates the metropolitan structure as the guide of the investments of capital reproduced in the region and that the EOM plays roles within the metropolitan division of labor in a more complex way than that identified in the past decades.

Presentamos con este texto un debate sobre la reestructuración metropolitana y sus cambios significativos en los arreglos espaciales regionales. Tenemos como recorte territorial el Extremo Oeste Metropolitano (EOM) de la Región Metropolitana de Rio de Janeiro, en la que, a través de análisis del desplazamiento diarios de los trabajadores, identificamos que además de las fuertes e históricas interacciones con el núcleo metropolitano también hay interacciones importantes entre los municipios analizados. Mostramos que la estructura metropolitana es la guía de las inversiones de capital que se reproducen en la región y que la EOM desempeña un papel dentro de la división metropolitana del trabajo de una manera más compleja que la identificada en las últimas décadas.

À partir de ce texte, nous présentons une discussion sur la restructuration métropolitaine et ses changements significatifs dans les arrangements spatiaux régionaux. Nous avons comme découpage territorial la sous-région du Extrême Ouest Métropolitain (EOM) de la Région Métropolitaine du Rio de Janeiro, dans laquelle, à travers des analyses du déplacement pendulaire des travailleurs, nous avons identifié qu'en plus des interactions fortes et historiques avec le noyau métropolitain, il y a aussi des interactions importantes entre les municipalités analysées. Nous montrons que la structure métropolitaine est le facteur directeur des investissements des capitales qui se reproduisent dans la région et que la EOM joue un rôle dans la division métropolitaine du travail d'une manière plus complexe que celle identifiée au cours des dernières décennies. 
ÍNDICE

Palavras-chave: reestruturação metropolitana, mobilidade pendular, Extremo Oeste da Região Metropolitana do Rio de Janeiro.

Mots-clés: restructuration métropolitaine, mobilité pendulaire, Extrême Ouest de la Région Métropolitaine de Rio de Janeiro.

Keywords: metropolitan restructuring, pendulum mobility, Extreme West of the Metropolitan Region of Rio de Janeiro.

Palabras claves: reestructuración metropolitana, desplazamiento diario, Extremo Oeste de la Región Metropolitana de Rio de Janeiro

\section{AUTORES}

\section{ANDRÉ SANTOS DA ROCHA}

Professor Adjunto do Departamento de Geografia e do Programa de Pós-graduação em Geografia da Universidade Federal Rural do Rio de Janeiro. Doutorado em Geografia (Universidade Federal do Rio de Janeiro). Coordenador do LAGEP. E-mail: asrgeo@gmail.com.

\section{LIRIAN MELCHIOR}

Professora Associada do Departamento de Geografia da Universidade Federal Rural do Rio de Janeiro. Doutorado em Geografia (Universidade Estadual Paulista). Pós-doutorado (City University of New York). E-mail: lirianmelchior@hotmail.com. 